\title{
DETERMINATION OF TOTAL PHENOLIC CONTENT, TOTAL FLAVONOID CONTENT, AND ANTIMUTAGENIC ACTIVITY OF ETHANOL EXTRACT NANOPARTICLES OF RHAPHIDOPHORA PINNATA (L.F) SCHOTT LEAVES
}

\author{
Sumaiyah $^{1 *}$, Masfria ${ }^{2}$ and A. Dalimunthe ${ }^{3}$ \\ ${ }^{1}$ Department of Technology Pharmacy, Faculty of Pharmacy, University of Sumatera Utara, \\ Medan-20155, Indonesia \\ ${ }^{2}$ Department of Chemistry Pharmacy, Faculty of Pharmacy, University of Sumatera Utara, \\ Medan-20155, Indonesia \\ ${ }^{3}$ Department of Pharmacology Pharmacy, Faculty of Pharmacy, University of Sumatera Utara, \\ Medan-20155, Indonesia \\ *E-mail : sumaiyah@usu.ac.id
}

\begin{abstract}
Phenolic and flavonoid compounds in plants are a natural source of antioxidants which can inhibit the development of several types of diseases in humans, such as cardiovascular diseases and cancer. This study aimed to determine total phenolic content, total flavonoid content, and antimutagenic activity of ethanol extract nanoparticles of Rhaphidophora pinnata (L.f) Schott leaves. The total phenolic content and the total flavonoid content of Rhaphidophora pinnata extract was determined with Folin-Ciocalteu method and aluminum chloride. The antimutagenic activity of the ethanol extract of Rhaphidophora pinnata leaves was evaluated based on the bone marrow micronucleus assay method. The total phenolic content of the ethanol extract of Rhaphidophora pinnata was $49.2 \mathrm{mg}$ gallic acid equivalent/g and the total flavonoid content was $21.8 \mathrm{mg}$ quercetin equivalent/g. The administration of ethanol extract nanoparticles of Rhaphidophora pinnata at a dose of 200, 400, $800 \mathrm{mg} / \mathrm{kgBW}$ could decrease the formation of micronucleus in the spinal cord of rats compared to the cyclophosphamide group $(P<0.05)$. The ethanol extract nanoparticles of Rhaphidophora pinnata had antimutagenic activity and dosedependent protection effects against cyclophosphamide - inducer of DNA oxidative damage.

Keywords: antimutagenic activity, nanoparticles, Rhaphidophora pinnata leaves, total flavonoid content, total phenolic content.
\end{abstract}

(C) RASĀYAN. All rights reserved

\section{INTRODUCTION}

Cancer is a disease which occurs due to the formation of abnormal cells. Cancer cases in Indonesia and some countries in the world continue to rise each year. Furthermore, WHO estimates that cancer would be the number one cause of death in the world in 2010, and 75 million people in the world will be affected by cancer in 2030. Research indicates that the cause of cancer is a disruption of the cell cycle due to mutations from the growth-regulating genes. The mutation of genes occurs because of mutagens, such as chemicals, radiation, free radicals, and infections of several types of virus (oncovirus group). One indicator of mutation is the formation of micronucleus. Micronucleus is a result of mutation of a broken whole chromosome and appears as a small nucleus within a cell. Mutations resulting from free radicals begin from the oxidation of unsaturated fatty acids in the cell membrane lipid layer. This reaction initiates the occurrence of chain-lipid oxidation which causes damage to the cell membrane. Further oxidation will occur in proteins which leads to DNA damage ${ }^{1,2}$.

Some reports state that antioxidants are compounds which can neutralize free radicals and have antimutagenic activity. The phenolic compounds, especially flavonoids and phenolic acids, are antioxidant compounds contained in plants $^{3}$. The phenolic compounds can neutralize free radicals, 
catalyze the formation of metallic chelate compounds, increase the activation of antioxidant enzymes, and inhibit the oxidation process. Several studies have also shown that phenolic compounds have a role in the modification of gene expression. Flavonoids, which are polyphenol compounds, can reduce free radicals, inhibit hydrolysis and oxidative enzymes, and have anti-inflammatory activity ${ }^{1,4}$.

A large number of chemical uses for various purposes results in an increased pollution of harmful chemicals into the environment. Toxicological studies provide information that most of the existing chemicals are mutagenic. Although human bodies are equipped with various defense mechanisms against mutagen, increased exposure to these chemicals can increase the chances of mutation. Therefore, a substance which can reduce the risk of mutation by mutagen is needed.

The effort of finding antimutagenic substances is mostly performed on natural materials, one of which is the Rhaphidophora pinnata (L.f) Scott leaves, Araceae family, which is one of the tropical plants in Indonesia. The ethanol extract of Rhaphidophora pinnata leaves contains secondary metabolite compounds, namely: flavonoids, tannin, alkaloids, glycosides, and steroids/triterpenoids. The content of polyphenols contained in the simplicial Rhaphidophora pinnata leaves is expected to able to reduce free radicals which can prevent DNA oxidation. The leaves are traditionally used as antibacterial, anticancer, rheumatism, and cough. Previous studies showed that the chloroform fraction and the ethanol extract of Rhaphidophora pinnata leaves have cytotoxic activity, inhibit proliferation, and induce apoptosis in MCF-7 of line cells ${ }^{5,6}$.

These days, the role of nanotechnology is important in the development of science and technology, such as particle nanotechnology which allows simplicial to be powdered to smaller sizes $(<1 \mu \mathrm{m})^{7}$. The application of nanotechnology is aimed to enhance the capability of the chemical compounds of Rhaphidophora pinnata leaves' activity. The contact area of the particle surface becomes larger in nano size which can increase the amount of the isolated active substances so that the antimutagenic activity becomes stronger ${ }^{8}$.

Based on the description above, the purpose of this study was to determine the total phenolic content, the total flavonoid content, and the antimutagenic activity of the ethanol extract nanoparticles of Rhaphidophora pinnata leaves in male rats using micronucleus methods in vivo which compared with cyclophosphamide as the inducer.

\section{EXPERIMENTAL}

\section{Materials}

Folin-Ciocalteu reagent (Sigma), sodium nitrite/ $\mathrm{NaNO}_{2}$ (Merck), aluminum chloride/ $\mathrm{AlCl}_{3}$ (Merck), aquades, methanol (Merck), quercetin, and gallic acid (Merck), cyclovid (Novell).

\section{Preparation of Nanoparticles Extracts}

The Rhaphidophora pinnata leaves were obtained from a local garden in Medan, North Sumatra, Indonesia. The leaves were identified in the Research Centre for Biology, LIPI, Bogor, Indonesia.

The dry simplicial leaves of Rhaphidophora pinnata were ground to a powder form and were extracted with percolation methods using ethanol as the solvent. The extract was concentrated using a rotary evaporator, then it was stored in a desiccator. The preparation of nanoparticles extract was according to the ball milling method with Arabic gum carriers and dextrin? 9

\section{Determination of Total Phenolic Contents}

The total phenolic content of ethanol extract of Rhaphidophora pinnata leaves was determined with UVVis spectrophotometer method using the Folin-Ciocalteu reagent ${ }^{1,10}$. Every $0.1 \mathrm{ml}$ of Rhaphidophora pinnata extract $200 \mu \mathrm{g} / \mathrm{ml}$ was stored in a test tube, added with 0.1 solutions of $50 \%$ Folin-Ciocalue reagent, then vortex for one minute. The solution was added $2 \mathrm{ml}$ of $2 \%$ sodium carbonate $\left(\mathrm{Na}_{2} \mathrm{CO}_{3}\right)$. This mixture was stored in a dark room for 30 minutes and the absorbance of the extract solution was read at $750 \mathrm{~nm}$ wavelength with the UV-Vis spectrophotometer. The total phenolic content was calculated based on the equation:

Total phenolic content $=\frac{\mathrm{x} \cdot \mathrm{V} \cdot \mathrm{DF}}{\mathrm{w}}$ 
Where:

$\mathrm{X}=$ Concentration $(\mathrm{ppm})$

$\mathrm{V} \quad=$ Volume of sample solution (extract) $(\mathrm{ml})$

$\mathrm{DF} \quad=$ Dilution Factor of the sample solution

$\mathrm{w} \quad=$ Sample weight $(\mathrm{g})$

\section{Determination of Total Flavonoid Contents}

The total flavonoid content was determined with colorimetry method of aluminum chloride with a spectrophotometer as the absorbance measurements and quercetin as the standard ${ }^{1,10}$. A sample of $25 \mathrm{mg}$ of ethanol extract of Rhaphidophora pinnata leaves was dissolved in $25 \mathrm{ml}$ of methanol, and then it was diluted until the concentration of the solution was $300 \mathrm{ppm}$. After $2 \mathrm{ml}$ of sample with a concentration of $300 \mathrm{ppm}$ was obtained, $0.1 \mathrm{ml}$ of $\mathrm{AlCl}_{3}, 0.1 \mathrm{ml}$ of sodium acetate, and $2.8 \mathrm{ml}$ of distilled water were added to the solution. The absorbance was determined using a visible spectrophotometer at a wavelength of $750 \mathrm{~nm}$. The flavonoid content was expressed in $\mathrm{mg}$ equivalent quercetin/g samples $(\mathrm{mg} \mathrm{Q} / \mathrm{g})$ and calculated based on the equation:

Total flavonoid content $=\frac{\mathrm{x} . \mathrm{V} . \mathrm{DF}}{\mathrm{w}}$
Where:
$\mathrm{x} \quad=$ Concentration $(\mathrm{ppm})$
$\mathrm{V} \quad=$ Volume of sample solution (extract) $(\mathrm{ml})$
$\mathrm{DF} \quad=$ Dilution Factor of sample solution
$\mathrm{W} \quad=$ Sample weight $(\mathrm{g})$

\section{Antimutagenic Activity}

This study was an experimental study, using male rats with a weight of 200-225 g. Prior to treatment, the rats were acclimatized for 14 days in a cage with controlled temperature $\left(28 \pm 2^{\circ} \mathrm{C}\right)$ and sufficient lighting. The rats were fed with sufficient pellets and water. The use of all testing animals in this study has been approved by the Animal Ethics Committee, Department of Biology, Faculty of Mathematics and Natural Sciences, the University of Sumatera Utara (No. 650/KEPH-FMIPA/2017).

A total of 20 male rats were divided randomly into five treatment groups, each consisting of four rats. Group I was given a $0.5 \%$ CMC-Na solution as the control. Group II was induced with cyclophosphamide (i.p $30 \mathrm{mg} / \mathrm{kg} \mathrm{BW}$ ). Group III, IV, and V were given the ethanol extract nanoparticles of Rhaphidophora pinnata leaves (EENRPL) at the dose of 200,400 , and $800 \mathrm{mg} / \mathrm{kgBW}$ for seven days. On the eighth day, the rats were induced intra-peritoneal with $30 \mathrm{mg} / \mathrm{kgBW}$ of cyclophosphamide. After 30 hours of the administration of cyclophosphamide, the rats were sacrificed by neck dislocation and its femoral bone marrow was collected with a syringe containing $0.3 \mathrm{ml}$ of SDS and put inside a microtube. The mixture of the bone marrow and SDS in the microtube was centrifuged at $1200 \mathrm{rpm}$ for five minutes, then the supernatant was discarded. The sediment was resuspended with two drops of SDS. After one drop of cell suspension was taken and place onto the slide, the cell was removed into a smear preparation using a slide eraser. Then, the slide was dried, fixed with methanol for five minutes, and dyed with Giemsa solutions for ten minutes. After the dye was removed by rinsing it with aquades, the smears were dried and observed under a microscope. The number of micronuclei cells was calculated per 200 cells of the smear preparations ${ }^{3}$.

\section{Statistical Analysis}

The rat bone marrow bioassay data were statistically analyzed using one-way analysis of variance (ANOVA), followed by the post-hoc Tukey test, with a significance level of $\mathrm{P}<0.05$.

\section{Determination of Total Phenolic Contents (TPC)}

\section{RESULTS AND DISCUSSION}

The phenolic and polyphenol compounds are secondary metabolites contained in plants. The phenolic compounds are antioxidants because of their ability to neutralize free radicals. The total phenolic content 
of the extracts can be determined by spectrophotometry using Folin-Ciocalteu reagents. The principle of this method is the formation of blue complex compounds due to the reaction between the phenolic compounds and the Folin-Ciocalteu which can be measured at a maximum wavelength. The phenolic compounds used as comparators were gallic acid.

Based on the research results, the equation of line obtained was: $y=0.00077 \mathrm{x}+0.03667 ; \mathrm{r}^{2}=0.998$. The total phenolic content of the ethanol extract of Rhaphidophora pinnata leaves found was $49.2 \mathrm{mg} \mathrm{GAE} / \mathrm{g}$ extract.

\section{Determination of Total Flavonoid Content (TFC)}

Flavonoids are polyphenol compounds contained in plants with benzo- $\gamma$-pyrone structures. The total flavonoid content in the extracts can be determined by colorimetry using aluminum chloride reagent. The principle of determining the flavonoid content with aluminum chloride method is the formation of a complex between aluminum chloride with keto clusters on a C-4 atom and hydroxy clusters on C-3 or C-5 atom, neighboring from the group of flavones and flavonols, forming a yellow stable compound. The compound used as a standard in this experiment was quercetin. This is because quercetin is a flavonoid from flavonol group which has keto clusters on a C-4 atom and hydroxyl clusters on neighboring C-3 and C-5 atom.

Based on the research results, the calibration curve of quercetin was obtained with equation: $y=0.02387$ $\mathrm{x}+0.12328 ; \mathrm{r}^{2}=0.999$. The total flavonoid content of the ethanol extract of Rhaphidophora pinnata leaves found was $21.8 \mathrm{mg}$ quercetin equivalent/g.

\section{Antimutagenic Activity}

The antimutagenic activity testing is a test to inhibit the occurrence of gene mutations in experimental animals. Mutation of genes is a condition, in which there is a change in the genetic material of living creatures, occurring suddenly, randomly, and would be inherited to the formation of subsequent living creatures due to the presence of mutagens ${ }^{11}$. The gene mutation cases can be known from the presence of micronucleus. Micronucleus is a small, round ubiquitous cell nucleus located around the cytoplasm of erythrocyte cells, having a size of approximately $1 / 20-1 / 5$ part of the parent nucleus. Micronucleus which is formed at the anaphase stage is an eccentric fragment or a chromosome left behind when cells perform mitosis as a result of damage or defects in chromosome yarn fixtures.

In this study, the formation of micronuclei was induced by cyclophosphamide. Cyclophosphamide is an alkylating agent which can bind to the cell component functional clusters, including DNA bases. DNA alkylation in the nucleus is the main mechanism of cell death. The cyclophosphamide is metabolized in the liver by isozyme cytochrome P450 to 4-hydroxy cyclophosphamide. The 4-hydroxy cyclophosphamide is oxidized into an aldophosphamide which is an active metabolite. Then, the resulting aldophosphamide is separated into mustard phosphamide and acrolein which are highly toxic compounds. The compounds cause the subsequent chromosomal fractures are seen as micronuclei of red blood cell formation in the spinal cord. ${ }^{11}$ In addition, some studies suggested that micronuclei formation is also triggered by an increased superoxide anion radical and hydroxyl due to the cyclophosphamide metabolism².

Based on the research results, the cyclophosphamide-induced group experienced an increase in the number of micronuclei compared to the control group (Table-1). The administration of the ethanol extract nanoparticles of Rhaphidophora pinnata leaves (EENRPL) with the dose variation of 200, 400, and 800 $\mathrm{mg} / \mathrm{kgBW}$ aimed to inhibit the formation of micronuclei after the induction with cyclophosphamide. The results showed that the antimutagenic activity of EENRPL increased along with the increasing dose. EENRPL at the dose of 200,400 , and $800 \mathrm{mg} / \mathrm{kgBW}$ could reduce the formation of micronuclei numbers significantly compared to the cyclophosphamide-induced group $(\mathrm{p}<0.05)$. The best antimutagenic activity was demonstrated by EENRPL at the dose of $200 \mathrm{mg} / \mathrm{kgBW}$ because this dose was able to decrease the formation of micronuclei similar to the control group which was not induced with cyclophosphamide.

In this study, the extract preparations were prepared in the form of nanoparticles in order to make the dosage of the preparations smaller than the conventional preparations. Previous research has shown that 
the ethanol extract of Rhaphidophora pinnata leaves had antimutagenic activity at the dose of 500, 750, and $1000 \mathrm{mg} / \mathrm{kgBW}^{12}$. The large dose variation led to the use of many raw materials and the administration of large extract preparations to the testing animals. Therefore, the researchers were interested in making the preparations in the form of nanoparticles. The purpose of nanoparticles was to reduce the size of the preparation particles to nano size. It was expected to increase the activity of the extract.

Table-1: The number of micronuclei after the administration of the ethanol extract nanoparticles of Rhaphidophora pinnata leaves

\begin{tabular}{c|c|c|c}
\hline No & Group & $\mathrm{n}$ & Number of Micronuclei \pm SEM \\
\hline 1 & Control & 4 & $29.00 \pm 1.78$ \\
\hline 2 & Na CMC 0.5\% + Cyclophosphamide & 4 & $35.50 \pm 1.32^{\#}$ \\
\hline 3 & EENRPL 200 mg/kgBW & 4 & $26.50 \pm 2.10^{*}$ \\
\hline 4 & EENRPL 400 mg/kgBW & 4 & $21.50 \pm 1.44^{* \#}$ \\
\hline 5 & EENRPL 800 mg/kgBW & 4 & $8.50 \pm 0.96^{* \#}$ \\
\hline
\end{tabular}

Note: EENRPL $=$ ethanol extract nanoparticles of Rhaphidophora pinnata leaves

*significantly different with the cyclophosphamide-induced group

\# significantly different with the control group

The antimutagenic activity of the extract of Rhaphidophora pinnata leaves was thought to be caused by the chemical content of this plant, both singly and synergistically. The results of phytochemical screening showed that the ethanol extract of Rhaphidophora pinnata leaves contains flavonoid compounds. Flavonoids are polyphenol compounds which have the ability to reduce free radical activity. Several studies have shown that flavonoids have antimutagenic and anticancer activity ${ }^{13,1}$. Besides, flavonoids might be able to protect DNA damage due to the presence of mutagen. However, the mechanism of inhibition of mutagenesis is highly complex and can work through various mechanisms ${ }^{14,2}$.

\section{CONCLUSION}

The ethanol extract nanoparticles of Rhaphidophora pinnata have antimutagenic activity and dosedependent protection effects against cyclophosphamide - the inducer of DNA oxidative damage.

\section{ACKNOWLEDGEMENT}

This research was funded by TALENTA University of Sumatera Utara in 2017.

\section{REFERENCES}

1. T.J. Makhafola, E.E. Elgorashi, L.J. McGaw, L. Verschaeve, and J.N. Eloff, BMC Complementary and Alternative Medicine, 16(490), 1(2016), DOI: 10.1186/s12906-016-1437-x

2. J. Kour, M.N. Ali, H.A. Ganaie, and N. Tabassum, Toxicology Reports, 4, 226(2017), DOI: 10.1016/j.toxrep.2017.05.001

3. L. B. Carvalho-Silva, M. D. V. Oliveira, V. S. Gontijo, W. F. Oliveira, P. B. M. C. Deragis, P. C. Stringheta, et al., Food Research International, 48, 180(2012), DOI:10.1016/j.foodres.2012.03.003

4. M. Carocho and I.C.F.R. Ferreira, Food Chem. Toxicol, 51, 15(2013), DOI: 10.1016/j.fct.2012.09.021

5. Masfria, U. Harahap, M.P. Nasution and S. Ilyas, Advances in Biological Chemistry, 3, 397(2013)

6. Masfria, U. Harahap, M.P. Nasution and S. Ilyas, International Journal of PharmTech Research, 6(4), 1327(2014)

7. C. Buzea, I.I.P. Blandino, and K. Robbie, Biointerphases, 2(4), 170(2007) 
RASĀYAN J. Chem.

Vol. 11 | No. 2 |505 - 510 | April - June | 2018

8. O. Kammona, K. Costas, Journal of Controlled Release, 161, 781(2012), DOI: 10.1016/j.jconrel.2012.05.040

9. Sumaiyah, Masfria, and A. Dalimunthe, In Proceedings of $2^{\text {nd }}$ International Conference on Advance of Pharmacy and Pharmaceutical Science, Indonesia (2017)

10. M.P. Srivastava, R. Tiwari, and N. Sharma, Journal of New Biological Reports, 2(2), 163(2013)

11. S. Atun, R. Arianingrum, E. Sulistyowati, and N. Aznam, Int. J. Chem. Anal. Sci., 4, 3(2013), DOI: 10.1016/j.ijcas.2013.03.004

12. Masfria, Sumaiyah, and A. Dalimunthe, Sci. Pharm, 85, 1(2017), DOI: 10.3390

13. V.C. Kumar, P.K.M. Nagarathna, S.C. Kulakarni, and N.S. Sainadh, Int. J. Pharm. Sci. Rev. Res., 18, 105(2013)

14. V. Jadhav and S.D. Biradar, International Journal of Medical and Biomedical Science, s2 (4), 46(2014)

[RJC-2068/2018] 